\title{
Factors associated with functional balance and mobility among elderly diabetic outpatients
}

\author{
Fatores associados ao equilíbrio funcional e à \\ mobilidade em idosos diabéticos ambulatoriais
}

Renata Cereda Cordeiro', José Roberto Jardim³, Monica Rodrigues Perracini'2, Luiz Roberto Ramos'

${ }^{1}$ Setor de Reabilitação Gerontológica do Lar Escola São Francisco - Centro de Reabilitação, Departamento de Medicina Preventiva da Universidade Federal de São Paulo (Unifesp), São Paulo, SP, Brasil ${ }^{2}$ Universidade Cidade de São Paulo (Unicid), São Paulo, SP, Brasil

${ }^{3}$ Disciplina de Pneumologia, Departamento de Medicina e Centro de Reabilitação Pulmonar do Lar Escola São Francisco/Unifesp
Correspondence to: Renata Cereda Cordeiro Setor de Reabilitação Gerontológica, Lar Escola São Francisco Rua dos Açores, 310 - Jardim Lusitânia 04032-060 - São Paulo, SP, Brasil renata.cereda@unifesp.br

Received in Oct/15/2008 Accepted in June/16/2009

\begin{abstract}
Objectives: To characterize balance and mobility among diabetic elderly outpatients and to estimate the extent to which functional balance and mobility abnormalities can be influenced by sociodemographic, clinical and other functional factors in a cross-sectional study. Methods: Ninety-one elderly (65+ years) outpatients were assessed. Mobility was evaluated by the Timed Up and Go Test (TUGT) and the balance, by the Berg Balance Scale (BS). Results: TUGT mean score was $15.65 \pm 5.9$ seconds and BS mean score was $49.31 \pm 7.3$ points. Using linear regression analysis $(\alpha \leq 0.05)$, significant and independent positive relationships were obtained between TUGT and age, daily activities (ADL/IADL), step strategy, and proprioceptive sensitivity. Factors negatively associated with BS were: ADL/IADL, step strategy, proprioceptive sensitivity, orthostatic hypotension $(\mathrm{OH})$ and conflictive sensory conditions. Conclusion: Elderly diabetic outpatients show abnormal balance and mobility related mainly to advanced age, disability, absence of step strategy, absence of proprioceptive sensitivity and presence of OH. Arq Bras Endocrinol Metab. 2009;53(7):834-43.
\end{abstract}

Keywords

Aged; frail elderly; activities of daily living; postural balance; mobility limitation; diabetes mellitus, type 2

\section{RESUMO}

Objetivos: Caracterizar o equilíbrio e a mobilidade de idosos diabéticos ambulatoriais e estimar o quanto suas anormalidades podem ser influenciadas por fatores sociodemográficos, clínicos e funcionais globais em um estudo transversal. Métodos: 91 idosos ( $65+$ anos) ambulatoriais foram avaliados quanto à mobilidade pelo Timed Up and Go Test (TUGT) e ao equilíbrio, pela Berg Balance Scale (BS). Resultados: A média dos escores doTUGT foi de 15,65 \pm 5,9 segundos e da BS, de 49,31 $\pm 7,3$ pontos. Empregando-se análise de regressão linear $(\alpha \leq 0,05)$, associações significantes positivas e independentes foram obtidas entre oTUGT e idade, atividades cotidianas, estratégia do passo atrás e sensibilidade proprioceptiva. Os fatores associados negativamente à BS foram: atividades cotidianas, estratégia do passo, sensibilidade proprioceptiva, hipotensão ortostática $(\mathrm{HO})$ e condições sensoriais conflituosas. Conclusão: Idosos diabéticos ambulatoriais apresentam equilíbrio e mobilidade prejudicados, relacionados principalmente à idade avançada, limitação para atividades diárias, ausência de estratégia de equilíbrio, prejuízo na sensibilidade proprioceptiva e a presença de HO. Arq Bras Endocrinol Metab. 2009;53(7):834-43

Descritores

Idoso; idoso frágil; atividades cotidianas; equilíbrio postural; limitação da mobilidade; diabetes melito tipo 2.

\section{INTRODUCTION}

F unctional independence is related directly to one's capacity of preservation of mobility in daily activi- ties, such as locomotion, sit-to-stand from a chair or getting up from the bed. Mobility demands functional balance as a pre-requisite and equally comprises a com- 
plex and a multidimensional task itself. A functional approach designed to clinically assess balance and mobility is employed to determine whether or not a balance disturb exists and if treatment is needed (1).

Diabetes mellitus (DM) is a chronic disease whose complications may cause damage to the balance maintenance systems, besides being a strong predictor of self-referred functional limitations, worse performance in lower limb functions and falls $(2,3)$. Postural unsteadiness is not a direct feature of DM, occurring only in association with chronic complications as neuropathy or aging (4-7). The prevalence of diabetic complications significantly increases with the duration of the disease, age, and poor patient glycemic control level. DM is also associated with geriatric conditions - falls, incontinence, low body mass index, dizziness, vision, hearing and cognitive impairments - and dependence on activities of daily living (ADL) (8).

Posturographic paradigm have identified that aging imposes changes in balance, such as lower amplitude of ankle strategy allied to neuromuscular slowing, agonistantagonist co-activation that results in higher utilization of the hip strategy even during subtle perturbations, a higher center of pressure amplitude and sway, decreased central integration, dependence on visual input (specially in dynamic control), impaired adaptive capacity during situations involving sensorial conflicts, a lower maximum voluntary inclination, and poor lateral control of sway (9-13).

It is not clear which is the main somatosensory determinant of postural instability; however, it has been observed that instability increases according to neuropathy severity (14-16). Diabetic individuals have worse adaptation to sensory conflictive situations, and present a greater dependence on visual input, similarly to what happens to aging $(14,16,17)$, but with a great difficulty in carrying out visual-vestibular compensation (18).

Posturography protocols are more accurate than functional examination for the assessment of subclinical balance systems alterations in elderly, diabetic and neuropathic patients. Most studies have focused on the understanding of each impaired subcomponent underlying functional balance limitation. However, it would be valuable for the health professionals to understand the functional performance resulting from the underlying balance impairments, as they have immediate clinical utility, low-cost and easy application. We hypothesize that elderly diabetic functional performance in tasks that involves general mobility and balance may be influenced by age, sex, global functional capacity in activities of daily living, foot abnormalities, pain in lower limbs, medications, orthostatic hypotension, comorbidities, sensorial organization and limits of stability. These tests are actually performed during evaluation of geriatric recurrent faller outpatients or in the rehabilitation setting, but rarely in the primary attention. Knowledge about determinants of disabled functional balance and mobility among diabetic elderly patients allows health professionals to plan preventive rehabilitation strategies that minimize the impact of functional and sensory complications of diabetes in a clinical setting.

The main objectives of this study are: (1) to describe functional balance and mobility performances among elderly diabetic outpatients; (2) to identify abnormalities in the performance of these functional tasks and (3) to estimate in which extent balance and mobility can be independently influenced by sociodemographic, clinical and self-related functional factors among these subjects in a cross-sectional study design.

\section{MATERIAL AND METHODS}

A cross-sectional exploratory study was conducted with community-dwelling older adults (65 years of age and over) of both sexes with a confirmed diagnosis of type 2 diabetes mellitus (19), followed up in an outpatient basis in a large academic medical school hospital in São Paulo, Brazil. Exclusion criteria were: diagnosis of dementia or cognitive deficits; severely impaired visual/auditory acuity; lower and upper-limb amputations in any level; lack of independent ambulation; chronic alcoholism. Informed consent was obtained prior to data collection and the study was approved by the local ethics committee.

\section{Procedures}

Participants were interviewed by means of a multidimensional questionnaire that included the following variables: sex, age, number of comorbidities, number of medications in use, insulin use, years of diagnosed DM, pain in the lower limbs (yes/no), complaint of instability or dizziness (yes/no), number of falls reported during the previous year, use of assistive devices for ambulation (yes/no), subjective perception of hearing and visual acuity (excellent/good or poor/ bad). The degree of independence in activities of daily living (ADL) was based on the number of activities in which the subject reported a certain difficulty from a checklist of 15 basic and instrumental ADL (getting in 
and out of bed, eating, combing one's hair, walking on flat ground, bathing, dressing, toileting, climbing stairs, taking medicines, walking a short distance, shopping, preparing meals, cutting toe nails, using public transport, grooming), from the "Brazilian OARS Multidimensional Functional Assessment Questionnaire" (BOMFAQ) (20). Cognitive status was assessed by the Mini-Mental State Exam (21).

Nutritional status was evaluated by the body mass index $\left(\mathrm{Kg} / \mathrm{m}^{2}\right)$. Visual inspection of the feet was conducted. Touch-pressure protective sensation of the feet was assessed by the 5.07 Semmes-Weinstein monofilament $(10 \mathrm{~g})$, assuming the following criteria: base of the first and fifth metatarsi; calcaneus and dorsal region of the feet between the first and the second metatarsi. The number of non-sensitive points or points whose localization was not perceived by the subject was registered. For vibratory sensation, a $128 \mathrm{~Hz}$ tuning fork was used on the medial and lateral malleoli, the base of the first metatarsi bilaterally, and on the dorsal surfaces. The presence or absence of sensation was registered as well. In the presence of ulcers and hyperkeratosis, the adjacent region was verified by means of both tests (protective and vibratory sensations). For verifying proprioceptive sensitivity, the participant was asked to identify the kept position of the great toe, after segment passive motion.

Orthostatic hypotension was detected by repeated systemic arterial pressure measurements through a portable sphygmomanometer at rest and after standing for three minutes.

The Clinical Test of Sensory Interaction and Balance (CTSIB) clinically assesses the influence of sensory integration in upright postural stability at three ranges of 30 seconds trials each (22). The test consists of six variables according to those six different sensory conditions that either eliminate input or produce inaccurate visual and surface orientation inputs. The trial was interrupted if the upper limbs were displaced from the trunk; if one or both knees were flexed; if either toes or heels were raised from the ground; if the subjects used a footstep to keep balance; or if the patient attempted to hold onto the technician during test execution.

The Reactive Balance Strategy (RBS) refers to the individual's ability to generate reactive postural synergies centralized at the ankles (ankle strategy) within the base of support, or out of the base of support (step strategy) as a response to manual external perturbations behind the patient, varying in intensity by the observer $(23)$.
Functional mobility and balance were assessed by the Timed Up and Go Test (TUGT) (24) and the Balance Scale (BS) (25), respectively. Each test-score represented one quantitative dependent variable. In the TUGT, participants were timed in seconds, starting from a seated position, standing up, walking three meters, turning, walking back and sitting down again. The longer the time, poorer was considered the mobility. The normal time to complete the task is between seven to ten seconds (24). The BS assesses functional performance based on 14 items common to daily life. Total scores varies from zero to 56 points, each score item deriving from an ordinal scale with five categories ranging from zero to 4 points. The higher the score, the better was the balance. Despite the high correlations between BS and TUGT $(r=0.76)$, each scale assesses different constructs of balance, that is to say, balance ability during activities when sitting and standing in the case of BS, and balance ability during timed locomotion and ambulatory transfers in the case of TUGT $(25,26)$.

\section{Statistical analysis}

Initially, descriptive statistical analysis was undertaken (central tendency measures, dispersion, kurtosis and skewness) to characterize the dependent variables (balance and mobility) as well as functional, clinical and sociodemographic factors. For preliminary analysis, independent-samples $\mathrm{T}$ test was used to compare the mean of the quantitative dependent variables (TUGT and BS) between gender and other dichotomous independent variables; for qualitative independent factors with $3+$ categories, analysis of variance (ANOVA) was used, both tests assuming a level of significance of 0.05 . Preliminary correlations between dependent variables and the quantitative independent variables were evaluated by Pearson's coefficient, considering a correlation above $30 \%(r= \pm 0.30)$ and descriptive level of 0.05 .

In a second step, associations with descriptive levels below 0.05 were selected for the following phase. With the aim of identifying balance and mobility determinants in the sample (factors independently associated with dependent variables), we carried out multiple linear regression analysis in blocks, assuming a level of significance of 0.05 . Multicollinearity between the selected independent variables was tested with the variance inflation factor (VIF). Any values between 0.19 and 5.30 were considered acceptable for absence of collinearity (27). 


\section{RESULTS}

Ninety one elderly patients participated in this study $(74.4 \pm 5.9$ years $)$, the majority being female $(65.9 \%)$, white $(70.0 \%)$ with a diagnosis of diabetes for less than 10 years $(56.5 \%)$ and mean length of time of $13.4 \pm 9.9$ years. Approximately $30 \%$ of them were using insulin as part of a therapeutic scheme.

Mean mobility by TUGT averaged $15.7 \pm 6.5$ seconds; $11.1 \%$ of the subjects carried out the functional task in less than 10 seconds, while the majority $(67.8 \%)$ spent between 10.01 and 20 seconds. The remaining $21.1 \%$ of the subjects completed the task in more than 20 seconds. Patients averaged $49.3 \pm 7.3$ points when taking the functional performance of balance (BS).
Patient's BMI averaged $28.0 \pm 3.6 \mathrm{~kg} / \mathrm{m}^{2}$. The mean number of comorbidities was of $3.4 \pm 2.1$ illnesses, and the number of medications taken was $3.8 \pm 2.2$. Sensitivity impairment was predominantly found in the protective modality: only $36.3 \%$ did not show sensitivity alterations in the test with monofilament. A great number of subjects complained of visual problems, classifying their general visual acuity perception as poor or bad (47.2\%), as regarding hearing acuity perception we found the contrary (Table 3 ). Approximately $41 \%$ of the subjects reported at least one fall occurrence during the last year, $15.4 \%$ of them presented recurrence. Tables 1 and 2 present the correlation between mobility and each independent variable of the study.

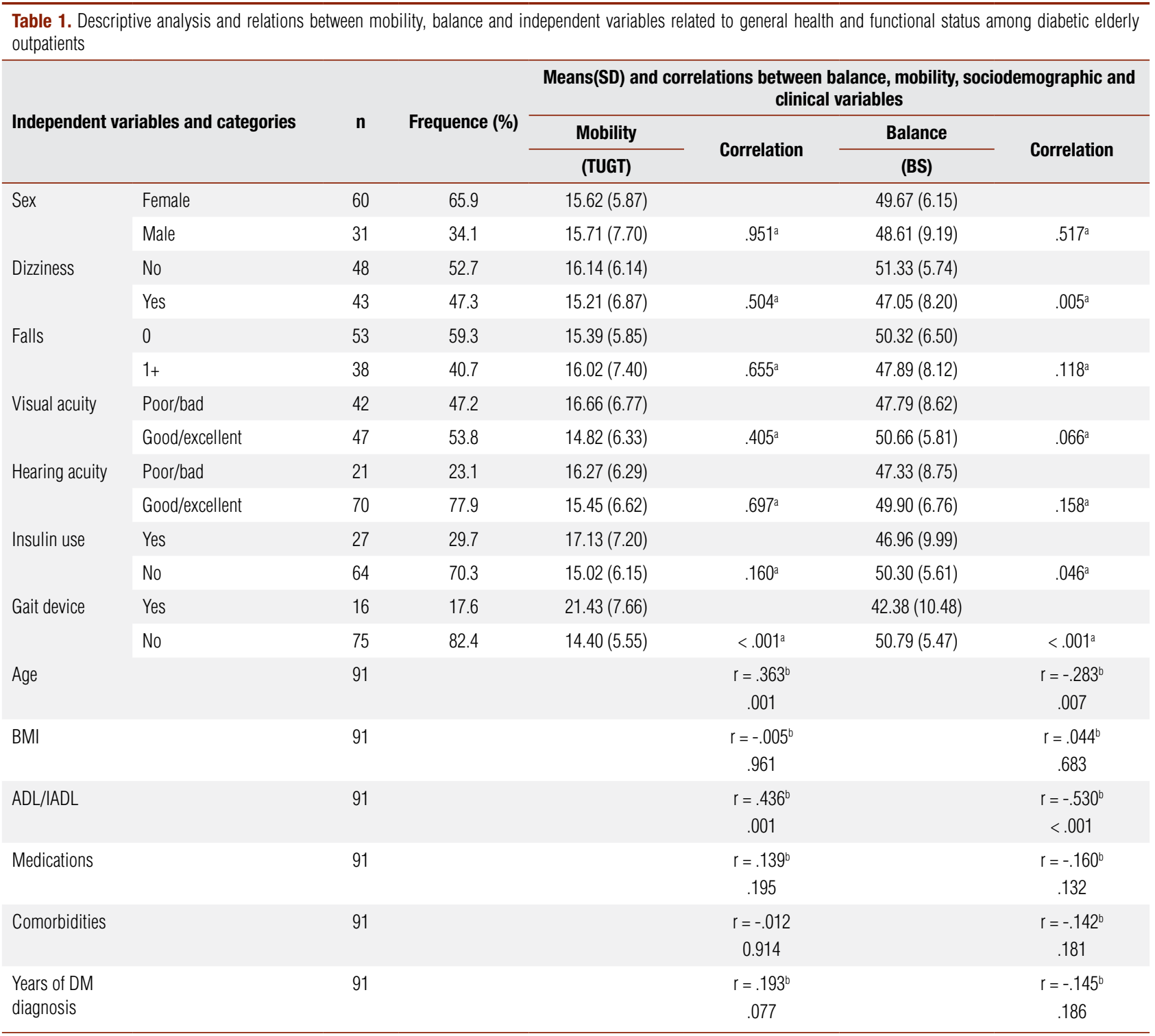

a Independent-samples T test; ${ }^{\circ}$ Pearson's coefficient. 


\begin{tabular}{|c|c|c|c|c|c|c|c|}
\hline \multirow{2}{*}{\multicolumn{2}{|c|}{ Independent variables and categories }} & \multirow{2}{*}{$\mathbf{n}$} & \multirow{2}{*}{ Frequence (\%) } & \multicolumn{4}{|c|}{$\begin{array}{l}\text { Means (SD) and correlations between balance, mobility and clinical/ } \\
\text { functional-related complications }\end{array}$} \\
\hline & & & & $\begin{array}{c}\text { Mobility } \\
\text { (TUGT) }\end{array}$ & Correlation & Balance & Correlation \\
\hline \multirow{3}{*}{ Orthostatic hypotension } & & & & & & & \\
\hline & Yes & 25 & 29.10 & $17.08(7.94)$ & & $46.44(9.81)$ & \\
\hline & No & 61 & 70.90 & $14.80(5.79)$ & $.144^{\mathrm{a}}$ & $50.48(5.85)$ & $.021^{\mathrm{a}}$ \\
\hline \multirow[t]{2}{*}{ Proprioceptive sensitivity } & Normal & 85 & 95.50 & $14.98(5.38)$ & & $50.00(5.99)$ & \\
\hline & Abnormal & 4 & 4.50 & $31.39(10.45)$ & $<.001^{\mathrm{a}}$ & $33.75(15.86)$ & $<.001^{\mathrm{a}}$ \\
\hline \multirow[t]{2}{*}{ Vibratory sensitivity } & Normal & 64 & 71.90 & $14.49(5.83)$ & & $51.33(4.97)$ & \\
\hline & Abnormal & 25 & 28.10 & $18.14(7.31)$ & $.016^{\mathrm{a}}$ & $44.76(9.62)$ & $<.001^{\mathrm{a}}$ \\
\hline \multirow[t]{3}{*}{ Foot abnormalities } & 0 & 16 & 17.60 & $13.68(4.70)$ & & $51.56(4.26)$ & \\
\hline & $1-3$ & 57 & 62.60 & $15.45(6.55)$ & & $49.50(7.53)$ & \\
\hline & $4+$ & 18 & 19.80 & $18.06(7.34)$ & $.137^{c}$ & $46.39(8.15)$ & $.105^{c}$ \\
\hline \multirow[t]{2}{*}{ Pain in lower limbs } & No & 43 & 47.3 & $13.74(6.11)$ & & $51.16(5.26)$ & \\
\hline & Yes & 48 & 52.7 & $17.41(6.44)$ & $.007^{\mathrm{a}}$ & $47.65(8.44)$ & $.021^{\mathrm{a}}$ \\
\hline \multirow[t]{2}{*}{ CTSIB 1} & Normal & 89 & 97.80 & $15.32(6.02)$ & & $49.71(6.85)$ & \\
\hline & Abnormal & 2 & 2.20 & $30.32(13.70)$ & $.001^{\mathrm{a}}$ & $31.50(3.54)$ & $<.001^{\mathrm{a}}$ \\
\hline \multirow[t]{2}{*}{ CTSIB 2} & Normal & 88 & 96.70 & $15.12(5.75)$ & & 50.08 & \\
\hline & Abnormal & 3 & 3.30 & $31.11(9.78)$ & $<.001^{\mathrm{a}}$ & 26.67 & $<.001^{\mathrm{a}}$ \\
\hline \multirow[t]{2}{*}{ CTSIB 3} & Normal & 88 & 96.70 & $15.25(6.01)$ & & $50.00(6.31)$ & \\
\hline & Abnormal & 3 & 3.30 & 27.41 (10.92) & $.001^{\mathrm{a}}$ & $29.00(5.00)$ & $<.001^{\mathrm{a}}$ \\
\hline \multirow[t]{2}{*}{ CTSIB 4} & Normal & 86 & 94.50 & $15.30(6.08)$ & & $49.92(6.87)$ & \\
\hline & Abnormal & 5 & 5.50 & $21.75(10.92)$ & $.030^{\mathrm{a}}$ & $38.80(6.94)$ & $.001^{\mathrm{a}}$ \\
\hline \multirow[t]{2}{*}{ CTSIB 5} & Normal & 66 & 72.50 & $14.42(5.45)$ & & $51.11(5.72)$ & \\
\hline & Abnormal & 25 & 27.50 & $18.85(7.96)$ & $.003^{\mathrm{a}}$ & $44.56(8.87)$ & $<.001^{\mathrm{a}}$ \\
\hline \multirow[t]{2}{*}{ CTSIB 6} & Normal & 77 & 84.60 & $14.57(5.35)$ & & $51.25(4.51)$ & \\
\hline & Abnormal & 14 & 15.40 & $21.54(9.02)$ & $<.001^{\mathrm{a}}$ & $38.64(10.23)$ & $<.001^{\mathrm{a}}$ \\
\hline \multirow[t]{2}{*}{ Reactive ankle strategy } & Normal & 46 & 50.50 & $14.26(6.93)$ & & $51.00(7.12)$ & \\
\hline & Abnormal & 45 & 49.50 & 17.05 (5.82) & $.042^{\mathrm{a}}$ & $47.58(7.14)$ & $.024^{\mathrm{a}}$ \\
\hline \multirow[t]{2}{*}{ Reactive step strategy } & Normal & 70 & 76.90 & $14.01(5.02)$ & & $51.17(5.47)$ & \\
\hline & Abnormal & 21 & 23.10 & 21.04 (7.97) & $<.001^{\mathrm{a}}$ & $43.10(9.15)$ & $<.001^{\mathrm{a}}$ \\
\hline \multirow[t]{2}{*}{5.07 monofilament } & & 91 & & & $r=.302$ & & $r=-.471$ \\
\hline & & & & & $<.001$ & & .004 \\
\hline
\end{tabular}

a Independent-samples T test; ${ }^{\circ}$ Pearson's coefficient; ' $A$ ANOVA.

Those independent variables that reached statistical criteria for presence of correlation with each dependent variable at the preliminary (bivariate) analysis were selected for linear regression models to explain the rank of independent association between these variables and functional balance and mobility. Linear regression analysis was conducted for both TUGT and BS, considering these numeric and dichotomic independent variables disposed in blocks as a similarity of constructs: neurosensitive symptoms, ADL/ IADL, clinical, sensory and motor strategies. In all models, sex and age variables were included (Tables 3 and 4).
Variables were removed one by one from each model based on the higher descriptive level (p-value) obtained until the final model was ascertained, whose $\mathrm{p}$ values should be below 0.05 .

Table 5 displays the multiple linear regression final model for balance and mobility impairment. The results shows that proprioceptive impairment represents an increment of approximately 14 seconds in timed TUGT performance $(\mathrm{p}<0.001)$. There was no collinearity between the independent variables (VIF between 1.028 and 1.538). 


\begin{tabular}{|c|c|c|c|c|c|c|}
\hline \multirow{2}{*}{$\begin{array}{l}\text { Group of independent } \\
\text { variables* }\end{array}$} & \multirow{2}{*}{$\begin{array}{l}\text { Independent variables for } \\
\text { the model } 1\end{array}$} & \multicolumn{2}{|c|}{ Unstandardized coefficients } & \multirow{2}{*}{ p-value } & \multicolumn{2}{|c|}{$\mathbf{9 5} \%$ Confidence interval for B } \\
\hline & & B & Std. error & & Lower bound & Upper bound \\
\hline \multirow[t]{6}{*}{ Neurosensitive symptoms } & Sex & -1.135 & 1.253 & 0.368 & -3.630 & 1.360 \\
\hline & Age & 0.315 & 0.094 & 0.001 & 0.129 & 0.501 \\
\hline & Pain in lower limbs & 1.921 & 1.152 & 0.100 & -0.373 & 4.215 \\
\hline & Proprioceptive sensitivity & 14.163 & 2.659 & $<0.001$ & 8.869 & 19.458 \\
\hline & 5.07 monofilament & 1.384 & 0.748 & 0.068 & $-0,105$ & 2.872 \\
\hline & Vibratory sensitivity & 0.430 & 1.481 & 0.772 & -2.519 & 3.380 \\
\hline \multirow[t]{9}{*}{ Sensory and motor stategies } & Sex & -0.647 & 1.319 & 0.625 & -3.273 & 1.978 \\
\hline & Age & 0.198 & 0.112 & 0.079 & -0.024 & 0.420 \\
\hline & Ankle strategy & 1.419 & 1.349 & 0.296 & -1.266 & 4.104 \\
\hline & Step strategy & 3.828 & 1.609 & 0.020 & 0.626 & 7.030 \\
\hline & ctsib2 & 9.547 & 4.769 & 0.049 & 0.626 & 19.042 \\
\hline & ctsib3 & 2.852 & 4.687 & 0.545 & 0.626 & 12.183 \\
\hline & ctsib4 & -0.738 & 2.882 & 0.799 & 0.626 & 5.000 \\
\hline & ctsib5 & 0.598 & 1.722 & 0.729 & 0.626 & 4.026 \\
\hline & ctsib6 & 0.883 & 2.435 & 0.718 & 0.626 & 5.731 \\
\hline \multirow[t]{4}{*}{ Functional activities } & Sex & -0.058 & 1.263 & 0.963 & -2.570 & 2.454 \\
\hline & Age & 0.267 & 0.104 & 0.012 & 0.060 & 0.474 \\
\hline & Gait device & 4.100 & 1.691 & 0.018 & 0.736 & 7.463 \\
\hline & Disability in ADL/IADL & 0.530 & 0.162 & 0.002 & 0.208 & 0.852 \\
\hline
\end{tabular}

* Blocks defined according to its conceptual similarity.

\section{DISCUSSION}

The mean TUGT time score (16 seconds approximately) indicated that this diabetic elderly sample demonstrated mobility limitations associated with functional frailty or impairments (24). The mean 49.3 points in BS clearly shows that elderly diabetic patients present some balance disability and this score is near to the cut-off score for fall risk according to Shumway-Cook and cols. (28).

Functional, clinical and sociodemographic characteristics of this sample does not substantially differ from those found for an elderly Brazilian population resident in a large metropolitan area, except regarding ADL/ IADL, and the occurrence of falls (40.7\%), higher than in other populational studies $(29,30)$. Almost $30 \%$ of the individuals reported difficulties to accomplish seven or more daily activities, while less than half of the subjects referred difficulty to accomplish three activities. The smaller occurrence was found at "no difficulty" category. These findings were significantly different from the population of community-dwelling elders, as $67.3 \%$ of them related difficulties in up to 3 activities $(31,32)$. Our sample comprised elderly volunteers recruited from an outpatient clinic facility, denoting a more frail functional profile in comparison to the communitydwelling elders.

The high number of self-related chronic comorbidities, similar to that found by Ramos and cols. (32), is remarkable. The mean 13.4 years of DM diagnosis was identical to Volpato and cols. (33). However, the functional profile was not the same as that found in the community: diabetic elders present a poorer global functional status. This is in agreement with the fact that elderly patients perceive their condition of health and well-being more by the capacity of carrying out independently ADL than by the number of medical diagnosis themselves. Among community-dwelling elders, disability represents an increased risk of death, allied to age, hospitalization reported within a period of six months, and cognitive impairment (31).

A strong independent association between functional balance measures (Balance Scale and Timed Up and Go Test) and referred ADL/IADL was found, in agreement with other studies $(20,24,34)$. Our patients were significantly functionally limited, with low adaptive performance. Elders with self-report of balance disability or weakness tend to be older, having less BMI, 


\begin{tabular}{|c|c|c|c|c|c|c|}
\hline \multirow{2}{*}{$\begin{array}{l}\text { Group of independent } \\
\text { variables* }\end{array}$} & \multirow{2}{*}{$\begin{array}{l}\text { Independent variables for } \\
\text { the model } 1\end{array}$} & \multicolumn{2}{|c|}{ Unstandardized coefficients } & \multirow[b]{2}{*}{$\mathrm{p}$-value } & \multicolumn{2}{|c|}{$\mathbf{9 5} \%$ confidence interval for B } \\
\hline & & B & $\begin{array}{l}\text { Standard } \\
\text { deviation }\end{array}$ & & Lower bound & Upper bound \\
\hline \multirow[t]{7}{*}{ Neurosensitive symptoms } & Sex & 1.615 & 1.483 & 0.280 & -1.341 & 4.571 \\
\hline & Age & -0.214 & 0.111 & 0.058 & -0.436 & 0.008 \\
\hline & Proprioceptive sensitivity & -11.624 & 3.063 & $<0.001$ & -17.728 & -5.519 \\
\hline & 5.07 Monofilament & -2.437 & 0.850 & 0.005 & -4.132 & -0.743 \\
\hline & Vibratory sensitivity & -2.643 & 1.729 & 0.131 & -6.089 & 0.803 \\
\hline & Orthostatic hypotension & -1.975 & 1.428 & 0.171 & -4.822 & 0.871 \\
\hline & Pain in lower limbs & -1.312 & 1.362 & 0.339 & -4.026 & 1.402 \\
\hline \multirow[t]{7}{*}{ Clinical } & Sex & -1.465 & 1.375 & 0.290 & -4.203 & 1.272 \\
\hline & Age & -0.271 & 0.112 & 0.018 & -0.495 & -0.047 \\
\hline & Orthostatic hypotension & -3.918 & 1.471 & 0.009 & -6.848 & -0.989 \\
\hline & Pain in lower limbs & -0.434 & 1.443 & 0.764 & -3.307 & 2.438 \\
\hline & Disability in ADL/IADL & -0.875 & 0.187 & $<0.001$ & -1.247 & -0.502 \\
\hline & MMSE & 0.091 & 0.150 & 0.547 & -0.208 & 0.389 \\
\hline & Insulin use & -3.291 & 1.418 & 0.023 & -6.114 & -0.468 \\
\hline \multirow[t]{7}{*}{ Sensory strategies } & Sex & -0.835 & 1.211 & 0.493 & -3.246 & 1.575 \\
\hline & Age & -0.046 & 0.105 & 0.663 & -0.256 & 0.163 \\
\hline & ctsib3 & -11.938 & 3.589 & 0.001 & -19.080 & -4.797 \\
\hline & ctsib4 & -2.533 & 2.750 & 0.360 & -8.006 & 2.939 \\
\hline & ctsib5 & -0.524 & 1.654 & 0.752 & -3.815 & 2.768 \\
\hline & ctsib6 & -7.848 & 2.349 & 0.001 & -12.522 & -3.174 \\
\hline & dizziness & -2.728 & 1.171 & 0.022 & -5.057 & -0.398 \\
\hline \multirow{6}{*}{$\begin{array}{l}\text { Motor strategies and functional } \\
\text { activities }\end{array}$} & Sex & -1.296 & 1.326 & 0.331 & -3.933 & 1.342 \\
\hline & Age & -0.104 & 0.109 & 0.344 & -0.321 & 0.113 \\
\hline & Disability in ADL/IADL & -0.710 & 0.169 & $<0.001$ & -1.045 & -0.374 \\
\hline & Ankle strategy & -0.795 & 1.321 & 0.549 & -3.422 & 1.832 \\
\hline & Step strategy & -4.475 & 1.570 & 0.006 & -7.598 & -1.351 \\
\hline & Gait device & -3.625 & 1.780 & 0.045 & -7.165 & -0.085 \\
\hline
\end{tabular}

* Blocks defined according to its conceptual similarity.

\begin{tabular}{|c|c|c|c|c|c|c|}
\hline \multirow{2}{*}{$\begin{array}{l}\text { Final } \\
\text { model }\end{array}$} & \multirow{2}{*}{$\begin{array}{c}\text { Remaining independent } \\
\text { variables }\end{array}$} & \multicolumn{2}{|c|}{ Unstandardized coefficients } & \multirow{2}{*}{ p-value } & \multicolumn{2}{|c|}{ 95\% confidence interval for B } \\
\hline & & B & Standard deviation & & Lower bound & Upper bound \\
\hline \multirow[t]{4}{*}{ TUGT } & Proprioceptive sensitivity & 13.711 & 2.388 & $<0.001$ & 8.960 & 18.461 \\
\hline & Reactive step strategy & 3.931 & 1.247 & 0.002 & 1.450 & 6.412 \\
\hline & Disability in ADL/IADL & 0.436 & 0.134 & 0.002 & 0.169 & 0.702 \\
\hline & Age & 0.247 & 0.088 & 0.006 & 0.072 & 0.423 \\
\hline \multirow[t]{6}{*}{ BS } & Proprioceptive sensitivity & -7.222 & 2.388 & 0.003 & -11.977 & -2.467 \\
\hline & Reactive step strategy & -4.025 & 1.186 & 0.001 & -6.386 & -1.664 \\
\hline & Disability in ADL/IADL & -0.601 & 0.130 & $<0.001$ & -0.861 & -0.341 \\
\hline & ctsib3 & -9.348 & 2.833 & 0.001 & -14.990 & -3.706 \\
\hline & ctsib6 & -5.221 & 1.545 & 0.001 & -8.297 & -2.145 \\
\hline & Orthostatic hypotension & -2.339 & 1.078 & 0.033 & -4.485 & -0.193 \\
\hline
\end{tabular}

TUGT/BS - dependent variables. 
and with worse performance in tests of global mobility (35). Diabetic subjects are usually younger and present decreased mobility, ADL/IADL disability, higher risk of lower limb function decline and an increased incidence of new disability (33). The negative effect of DM on the physical function occurs in addition to the presence of chronic complications over time (33).

Poor balance is a strong intrinsic risk factor for falls; however, in our sample, we found that balance and mobility were similar among faller and non-faller elderly. The cross-sectional design of our study makes impossible to draw conclusions about the temporal sequence of the events of functional disability and falls. Nevertheless, there are some early evidences that increased risk of falls in elderly diabetic individuals are associated with female gender, age over 75 years, poor diabetic control, use of walking aids and previous stroke (36).

Several studies demonstrated association between diabetes and mobility limitations $(5,37)$, also reporting balance disorders and weakness $(35,38)$. Although in the present study we did not directly test biomechanical aspects such as muscular strength, torque and range of motion, they are a crucial part of the plan of action execution as a reaction to internally or externally provoked balance disturbances $(1,39)$. In stabilometry, increased postural sway of neuropathic patients is more associated with timing and accuracy of nervous control than strength (40). In the case of aging with neuropathy, a delay in the activation of postural reaction occurs even in the presence of visual input $(1,18,41)$. Possible compensations for it would be increasing the intensity of the responses, using greater anticipatory control or even increasing dependence on visual information $(1,39)$. Balance and gait differences between diabetic with and without neuropathies are the result of touch sensibility and not muscular strength or vision $(42,43)$.

Almost half of our patients presented an abnormal performance in the clinical test of reactive-balancestrategy. Underestimation of cases of reactive strategy disability may have occurred. It is known that this test is not as susceptible to subtle alterations if compared to dynamic posturography with electromyography protocol, which characterizes dynamic and cinematically complex movement patterns (1). The use of a functional test, that aims to obtain qualitative data from direct observation of disorders in balance responses to external disturbances, was justified in an attempt to contemplate a constitutive aspect of the concept of balance assumed. This is not a validated method despi- te its extensive application in the therapeutic setting. We observed that both impairments in motor reactive strategies, ankle and step were associated with the two other functional tests. However, independent association between impaired balance and mobility occurred only with impaired step strategy.

The ankle strategy is the first strategy used to respond to any external perturbation and is appropriate to the maintenance of balance for small sways when standing on a firm surface. On the other hand, taking a step to recover equilibrium is a common strategy especially during gait and when keeping the feet in place is not relevant. Elderly individuals at risk of falling tend to use the stepping, reaching and hip strategies more than others with low risk of falling (39).

Both elderly and neuropathic diabetic subjects exhibit a propensity to alterations in movement patterns or absence of ankle strategy (12-14). In the present study, we found a low frequency of elders with abnormal step strategy, indicating that they were unable to recover protectively from a center of body mass displacement outside the base of support, in order to avoid a fall. The absence of this motor strategy, in opposition to ankle strategy, may be an explanation for balance and mobility disorders. Thus, functional balance and mobility disorders can be taken as a severely impaired reactive strategy and not as small age-related changes.

Proprioceptive sensitivity was the main determinant of balance and mobility of the three sensory systems evaluated. In our study, impairments in this sensitive modality represent an addition of 14 seconds in TUGT performance and a decrease of more than nine points in BS. Previously, it has been demonstrated that in healthy elderly people the dynamic position sense of the ankle contributes to alterations in the whole physical function and balance (44).

Cutaneous-protective and vibratory modalities lost their explanatory power after linear regression analysis. Our study is in agreement with Nardone and Schieppati $(40)$, who also did not find a relationship between the clinical test of tactile sensitivity and balance in diabetic patients with neuropathy, contrary to the notion that the afferent cutaneous fibers would play a critical role in postural control.

The ability of re-weight sensory information depending on the sensory context is important for maintaining stability when an individual moves from one sensory context to another (39). Sensory integration measured by CTSIB showed an independent association betwe- 
en balance and the conditions of sensory conflict with unstable or stable platform and, specially, with visual and vestibular conflict. The results from the regression analysis corroborate the clinical hypothesis that diabetic elders are visually-dependent as described by ShumwayCook and Woollacott (23). These results allow us to conclude that an altered proprioception or impaired sensory interaction increases the chance of balance and mobility disability among elderly diabetic patients.

Compared to TUGT, BS includes tasks that involve a narrow base of support (items 7 and 12-14 of the scale). It is recommended that a test of unipedal stance could be used clinically in elders with moderate peripheral neuropathy diagnosed by electroneuromyography, even in the absence of difficulties reported by the patient. However, normal situations in the daily routine could be sensitive enough to identify balance deficits in this population (45). The difficulty in maintaining a narrow support base is associated with the somatosensory input affected in diabetic patients with neuropathy. Hurvitz and cols. (46) showed that the test of unipedal stance is a good predictor of peripheral neuropathy, with $83 \%$ of sensitivity and $71 \%$ of specificity, added to a negative predictive value of $90 \%$ and positive of $57 \%$. If abnormalities are found in this simple test taken at the primary attention, clinical and electrophysiological evaluation should confirm the presence of neuropathy (46).

Orthostatic hypotension was independently associated with functional balance in the present study. Despite weak evidence of fall-risk among communitydwelling elders, in diabetic elders autonomous neurological function influences postural adaptation, even in subjects without clinical diagnosis of orthostatic hypotension (47).

The generalization of our results is limited to elderly diabetic outpatients. Exploratory interest on strictly functional balance and mobility motivated our decision to characterize and to explain these abnormalities in the elderly diabetic outpatient population. To reach this objective, we did not use any accurate test to diagnose neuropathy, as we were not aiming to investigate the causal relationship between this diagnosis and their referred impairments. Our study provides insights on the role that simple measurements play in the delimitation of abnormalities in complex functions, such as balance and mobility in the clinical routine at primary attention. We can infer that low self-referred functional capacity, the absence of step strategy, abnormality in proprioceptive sensation and in sensory interaction during conflict situations, as well as the presence of orthostatic hypotension, determine poor functional performance in daily tasks, which could be a potentially increased risk for falls. It is recommended that health care staff includes these factors in a comprehensive assessment of the elderly diabetic, considering that they can explain balance and mobility abnormalities. Besides, the identification of these factors can orient an early individualized rehabilitation program.

Acknowledgements: the authors would like to thank the Brazilian Agency Coordenação de Aperfeiçoamento Profissional de Nível Superior (Capes) for the financial support.

Disclosure: no potential conflict of interest relevant to this article was reported.

\section{REFERENCES}

1. Horak FB, Henry SM, Shumway-Cook A. Postural perturbations: new insights for treatment of balance disorders. Phys Ther. 1997;77(5):517-33.

2. Maurer MS, Burcham J, Cheng H. Diabetes mellitus is associated with an increased risk of falls in elderly residents of a long-term care facility. J Gerontol A Biol Sci Med. 2005;60(9):1157-62.

3. Perkowski LC, Stroup-Benham CA, Markides KS, Lichtenstein MJ, Angel RJ, Guralnik JM, et al. Lower-extremity functioning in older Mexican Americans and its association with medical problems. J Am Geriatr Soc. 1998;46(4):411-8.

4. Cavanagh PR, Simoneau GG, Ulbrecht JS. Ulceration, unsteadiness, and uncertainty: the biomechanical consequences of diabetes mellitus. J Biomech. 1993;26 Suppl 1:23-40.

5. Kriegsman DM, Deeg DJ, van Eijk JT, Penninx BW, Boeke AJ. Do disease specific characteristics add to the explanation of mobility limitations in patients with different chronic diseases? A study in The Netherlands. J Epidemiol Community Health. 1997;51(6):676-85.

6. Resnick HE, Stansberry KB, Harris TB, Tirivedi M, Smith K, Morgan $P$, et al. Diabetes, peripheral neuropathy, and old age disability. Muscle Nerve. 2002;25(1):43-50.

7. Simoneau GG, Ulbrecht JS, Derr JA, Becker MB, Cavanagh PR. Postural instability in patients with diabetic sensory neuropathy. Diabetes Care. 1994;17(12):1411-21.

8. Cigolle CT, Langa KM, Kabeto MU, Tian Z, Blaum CS. Geriatric conditions and disability: the Health and Retirement Study. Ann Intern Med. 2007;147(3):156-64.

9. Camicioli R, PanzerVP, Kaye J. Balance in the healthy elderly: posturography and clinical assessment. Arch Neurol. 1997;54(8):976-81.

10. Cohen $\mathrm{H}$, Heaton LG, Congdon SL, Jenkins HA. Changes in sensory organization test scores with age. Age Ageing. 1996;25(1):39-44.

11. King MB, Judge JO, Wolfson L. Functional base of support decreases with age. J Gerontol. 1994;49(6):M258-63.

12. Manchester D, Woollacott M, Zederbauer-Hylton N, Marin O. Visual, vestibular and somatosensory contributions to balance control in the older adult. J Gerontol. 1989;44(4):M118-27.

13. Perrin PP, Jeandel C, Perrin CA, Bene MC. Influence of visual control, conduction, and central integration on static and dynamic balance in healthy older adults. Gerontology. 1997;43(4):223-31.

14. Giacomini PG, Bruno E, Monticone G, Di Girolamo S, Magrini A, Parisi $L$, et al. Postural rearrangement in IDDM patients with peripheral neuropathy. Diabetes Care. 1996;19(4):372-4. 
15. Oppenheim U, Kohen-Raz R, Alex D, Kohen-Raz A, Azarya M. Postural characteristics of diabetic neuropathy. Diabetes Care. 1999;22(2):328-32.

16. van Deursen RW, Simoneau GG. Foot and ankle sensory neuropathy, proprioception, and postural stability. J Orthop Sports Phys Ther. 1999;29(12):718-26.

17. Boucher $P$, Teasdale N, Courtemanche R, Bard C, Fleury M. Postural stability in diabetic polyneuropathy. Diabetes Care. 1995;18(5):638-45.

18. Jauregui-Renaud K, Kovacsovics B, Vrethem M, Odjvist LM, Ledin T. Dynamic and randomized perturbed posturography in the follow-up of patients with polyneuropathy. Arch Med Res. 1998;29(1):39-44.

19. Alberti KG, Zimmet PZ. Definition, diagnosis and classification of diabetes mellitus and its complications. Part 1: diagnosis and classification of diabetes mellitus provisional report of a WHO consultation. Diabet Med. 1998;15(7):539-53.

20. Ramos LR, Perracini MR, Rosa TE, Kalache A. Significance and management of disability among urban elderly residents in Brazil. J Cross Cult Gerontol. 1993;8(4):313-23.

21. Folstein MF, Folstein SE, McHugh PR. "Mini-mental state". A practical method for grading the cognitive state of patients for the clinician. J Psychiatr Res. 1975;12(3):189-98.

22. Shumway-Cook A, Horak FB. Assessing the influence of sensory interaction of balance. Suggestion from the field. Phys Ther. 1986;66(10):1548-50.

23. Shumway-Cook A, Woollacott M. Motor control: theory and practical applications. Baltimore: Williams and Wilkins; 1995.

24. Podsiadlo D, Richardson S. The timed "Up \& Go": a test of basic functional mobility for frail elderly persons. J Am Geriatr Soc. 1991;39(2):142-8.

25. Berg KO, Wood-Dauphinee SL, Williams Jl, Maki B. Measuring balance in the elderly: validation of an instrument. Can J Public Health. 1992;83 Suppl 2:S7-11.

26. Hatch J, Gill-Body KM, Portney LG. Determinants of balance confidence in community-dwelling elderly people. Phys Ther. 2003;83(12):1072-9.

27. Hair Jr JR, Smith DM, et al. Multivariate data analysis: with readings. 4 ed. New Jersey: Prentice Hall; 1995.

28. Shumway-Cook A, Baldwin M, Polissar NL, Gruber W. Predicting the probability for falls in community-dwelling older adults. Phys Ther. 1997;77(8):812-9.

29. Perracini MR, Ramos LR. [Fall-related factors in a cohort of elderly community residents]. Rev Saude Publica. 2002;36(6):709-16.

30. Tinetti ME, Speechley M, Ginter SF. Risk factors for falls among elderly persons living in the community. $\mathrm{N}$ Engl $\mathrm{J}$ Med. 1988;29;319(26):1701-7.

31. Ramos LR, Simoes EJ, Albert MS. Dependence in activities of daily living and cognitive impairment strongly predicted mortality in older urban residents in Brazil: a 2-year follow-up. J Am Geriatr Soc. 2001;49(9):1168-75.
32. Ramos LR, Toniolo J, Cendoroglo MS, Garcia JT, Najas MS, Perracini $\mathrm{M}$, et al. Two-year follow-up study of elderly residents in $\mathrm{S}$. Paulo, Brazil: methodology and preliminary results. Rev Saude Publica. 1998;32(5):397-407.

33. Volpato S, Blaum C, Resnick H, Ferrucci L, Fried LP, Guralnik JM. Comorbidities and impairments explaining the association between diabetes and lower extremity disability: The Women's Health and Aging Study. Diabetes Care. 2002;25(4):678-83.

34. Bogle Thorbahn LD, Newton RA. Use of the Berg Balance Test to predict falls in elderly persons. Phys Ther. 1996;76(6):576-83; discussion 84-5.

35. Leveille SG, Fried LP, McMullen W, Guralnik JM. Advancing the taxonomy of disability in older adults. J Gerontol A Biol Sci Med Sci. 2004;59(1):86-93.

36. Tilling LM, Darawil K, Britton M. Falls as a complication of diabetes mellitus in older people. J Diabetes Complications. 2006;20(3):158-62.

37. Maty SC, Fried LP, Volpato S, Williamson J, Brancati FL, Blaum CS. Patterns of disability related to diabetes mellitus in older women. J Gerontol A Biol Sci Med Sci. 2004 ;59(2):148-53.

38. Daubney ME, Culham EG. Lower-extremity muscle force and balance performance in adults aged 65 years and older. Phys Ther. 1999;79(12):1177-85.

39. Horak FB. Postural orientation and equilibrium: what do we need to know about neural control of balance to prevent falls? Age Ageing. 2006;35 Suppl 2:ii7-ii11.

40. Nardone A, Schieppati M. Group II spindle fibres and afferent control of stance. Clues from diabetic neuropathy. Clin Neurophysiol. 2004;115(4):779-89.

41. Lafond D, Corriveau H, Prince F. Postural control mechanisms during quiet standing in patients with diabetic sensory neuropathy. Diabetes Care. 2004;27(1):173-8.

42. Bergin PS, Bronstein AM, Murray NM, Sancovic S, Zeppenfeld DK. Body sway and vibration perception thresholds in normal aging and in patients with polyneuropathy. $\mathrm{J}$ Neurol Neurosurg Psychiatry. 1995;58(3):335-40.

43. Menz HB, Lord SR, St George R, Fitzpatrick RC. Walking stability and sensorimotor function in older people with diabetic peripheral neuropathy. Arch Phys Med Rehabil. 2004;85(2):245-52.

44. Madhavan S, Shields RK. Influence of age on dynamic position sense: evidence using a sequential movement task. Exp Brain Res. 2005;164(1):18-28.

45. Richardson JK, Ashton-Miller JA, Lee SG, Jacobs K. Moderate peripheral neuropathy impairs weight transfer and unipedal balance in the elderly. Arch Phys Med Rehabil. 1996;77(11):1152-6.

46. Hurvitz EA, Richardson JK, Werner RA. Unipedal stance testing in the assessment of peripheral neuropathy. Arch Phys Med Rehabil. 2001;82(2):198-204.

47. Yamamoto R, Kinoshita T, Momoki T, Arai T, Okamura A, Hirao K, et al. Postural sway and diabetic peripheral neuropathy. Diabetes Res Clin Pract. 2001;52(3):213-21. 